\title{
A review of glycaemic changes on vision in phakic, aphakic and pseudophakic people with diabetes
}



Background: One of the leading causes of preventable blindness is cataract affecting approximately 18 million people worldwide. Twenty per cent of cataract operations worldwide are performed on people with diabetes mellitus (PDM).

Aim: The aim of this review article is to analyse the scientific literature relating to visual changes associated with diabetes mellitus (DM) in pseudophakic, aphakic and phakic people, and to discuss the consequences of these changes for optometrists.

Method: A literature search was conducted on PubMed, the University of KwaZulu-Natal Libraries and Google Scholar databases from August 2017 to August 2018.

Results: Acute and chronic hyperglycaemia in DM causes myopia in phakic PDM, whilst in aphakic PDM it causes a hyperopic shift in refraction. It has been reported that contrast sensitivity and visual acuity are affected by changes in blood glucose. People with DM have increased central corneal thickness as compared to non-diabetics, whilst only the posterior corneal curvature is affected by hyperglycaemia in PDM. No evidence exists on the effects of glycaemic changes in pseudophakes.

Conclusion: It should be noted that high blood glucose level (BGL) induces transient myopia and hyperopia in chronic phakic PDM and aphakic PDM, respectively. All refractive procedures, including prescription of spectacles, corneal refractive procedures and lens extraction, should be deferred until normalisation of BGL in phakic and pseudophakic PDM, as higher sugar levels affect corneal curvature and thickness and overall vision.

Keywords: hyperglycaemia; people living with diabetes mellitus; phakic; aphakic; pseudophakic; vision; refractive error; visual acuity; contrast sensitivity; corneal curvature; corneal thickness.

\section{Introduction}

One of the leading causes of preventable blindness is cataract affecting approximately 18 million people worldwide. ${ }^{1}$ Diabetes mellitus (DM) affects $6 \%$ of the South African population. In KwaZulu-Natal, this prevalence is $12.5 \%$, which is higher than the national prevalence. ${ }^{2}$ Prediabetes is a condition in which insulin resistance causes blood glucose levels (BGL) to be higher than normal but not high enough to be regarded as non-insulin-dependent diabetes, which is prevalent in approximately 5 million South Africans. ${ }^{3}$ The International Diabetes Federation (IDF) has found that 366 million people have DM globally and has predicted this number to rise to 552 million by $2030 .^{3}$

Diabetes mellitus is a group of metabolic diseases, characterised by high BGL resulting from deficient insulin secretion, insulin action or both. ${ }^{4}$ Currently, it is classified on the basis of the pathogenic process that leads to hyperglycaemia. Under this classification, the terms type 1 diabetes mellitus (T1 DM) and type 2 diabetes mellitus (T2 DM) have replaced insulin-dependent $\mathrm{DM}$, juvenile-onset diabetes and non-insulin-dependent DM, respectively, for adult-onset diabetes. ${ }^{4}$ Common symptoms of DM are polyuria, polydipsia, polyphagia, weight loss and blurred vision. ${ }^{4}$

Glycaemic changes are assessed using the following tests to indicate DM: ${ }^{4,5}$

- Fasting plasma glucose:

$\geq 7.0 \mathrm{mmol} / \mathrm{L}$

- Urine glucose:

\section{$\geq 0.8 \mathrm{mmol} / \mathrm{L}$}


- Haemoglobin A1C:

$>6.5 \%$

- Fasting blood glucose:

$>7 \mathrm{mmol} / \mathrm{L}$

- Random or casual blood glucose:

- Glucose tolerance test:

$11 \mathrm{mmol} / \mathrm{L}$

$>11.1 \mathrm{mmol} / \mathrm{L}$ after $2 \mathrm{~h}$

The chronic hyperglycaemic condition of DM is related to persistent damage and dysfunction of various organs, that is, eyes, kidneys, nerves, heart and the blood vessels. In the eye, long-term complications of DM include retinopathy, which may lead to potential irreversible loss of vision. The acute glycaemic changes in phakic people with diabetes mellitus (PDM) cause fluctuations in distance and near vision. ${ }^{4,6}$

\section{Background}

In PDM, the intracellular accumulation of sorbitol owing to poor metabolic control causes changes in the crystalline lens proteins, which result in cataract. ${ }^{7}$ Cataract is two to five times more frequent in PDM, thereby increasing the likelihood of pseudophakia in this group. ${ }^{1}$

The term 'pseudophakia' refers to having an artificial intraocular lens (IOL) implanted after the natural eye lens is removed. During cataract surgery, the natural cloudy lens is replaced by an IOL. ${ }^{8}$ The most common type of IOL used is the monofocal IOL, which allows the patient to focus at a certain distance; however, there are multifocal and accommodating IOL that allows the patient to see at different distances. A point to note is that the crystalline lens is metabolically active and requires nourishment in order to maintain its growth and transparency, whilst the IOL is not metabolically inert. ${ }^{9}$

People with DM account for up to $20 \%$ of all cataract procedures, with this number increasing annually ${ }^{1}$; evidence of the effect of glycaemic changes in pseudophakic PDM on vision is limited. The consequences of this on the management of pseudophakic PDM in clinical settings require addressing. This suggests that the number of diagnosed and undiagnosed pseudophakic PDM visiting optometrists is likely to increase exponentially in the light of the IDF prediction of 552 million PDM by 2030.

The occurrence of transitory refractive changes in phakic PDM was recognised as early as in $1873,{ }^{7,10}$ Refractive error is affected by the changes in either or all of corneal thickness, corneal curvature, lenticular thickness and axial length. ${ }^{11} \mathrm{~A}$ change towards hyperopia in phakic PDM occurred in the patients with reduced BGL, but the effect in pseudophakic PDM is yet to be established. ${ }^{12}$

Contrast sensitivity (CS) can be used to grade and monitor the progression of diabetic retinopathy as there is a greater loss of CS in severe diabetic retinopathy. ${ }^{13}$ Fluctuation of BGL in DM has been known for many years to cause change in visual acuity (VA), but there is a lack of evidence on the effect on pseudophakic PDM and on CS. There are no significant changes in the overall anterior corneal curvature before and after glycaemia control in phakic PDM; ${ }^{14,15}$ however, there is evidence of significant change in the flattest corneal meridian. ${ }^{16}$
Acute fluctuations in BGL had no effect in the corneal thickness of phakic PDM. ${ }^{17}$ There are conflicting reports on the effect of acute changes of BGL on the overall corneal curvature in phakic PDM. ${ }^{15,18,19}$

This present article could be beneficial towards effectively managing refractive error in acute glycaemic changes in phakic, aphakic and pseudophakic PDM in terms of the effect of glycaemic changes in pseudophakic, aphakic and phakic PDM on refraction, VA, CS, corneal thickness and corneal curvature. It could also isolate the involvement of the remaining natural refractive surface of the cornea on vision in pseudophakic and aphakic PDM.

The aim of this review article was to analyse the scientific literature relating to visual changes associated with DM in pseudophakic, aphakic and phakic PDM and discuss the consequences of these changes for optometrists.

\section{Method}

The study is structured as a narrative review. A comprehensive literature search was conducted on PubMed, the University of KwaZulu-Natal Libraries and Google Scholar databases from August 2017 to August 2018. The search included articles from 1976 to 2018. Inquiries were made using the following keywords in various combinations: 'pseudophakic diabetes mellitus', 'refractive error changes of diabetes mellitus', 'corneal changes in diabetes' and 'diabetes mellitus'. All relevant English language publications were included. All included studies were thematically analysed and organised.

\section{Ethical considerations}

Ethical clearance was obtained from the Biomedical Research Ethics Committee of the University of KwaZulu-Natal (number BE230/18).

\section{Results \\ Refractive error in people with diabetes mellitus}

Refractive error is influenced by changes in corneal thickness, corneal curvature, lenticular thickness and axial length or a combination of all of these. ${ }^{11}$ As early as in 1873, changes in BGL have been recognised to affect vision in PDM. ${ }^{7}$ Refractive error changes are very common in PDM, and sometimes it could be the first sign to indicate the existence of the condition. Transient refractive changes are immensely dependent on the degree of BGL. ${ }^{20}$ Studies ${ }^{7,12,18,21,22}$ were conducted on PDM that had no diabetic retinopathy, with the exception of one study ${ }^{23}$ that included mild diabetic retinopathy with no macular oedema. Table 1 shows the various studies comparing the effect of acute glycaemic changes on phakic and aphakic PDM. . $12,18,21,23,24,25^{2}$

\section{Aphakic and pseudophakic people with diabetes mellitus}

As early as in 1976, Gwinup et al. ${ }^{21}$ studied both transient and chronic changes in BGL on refraction in both phakic PDM 
TABLE 1: Effect of glycaemic changes on refraction or refractive error in people with diabetes mellitus.

\begin{tabular}{|c|c|c|c|c|c|c|c|c|c|c|}
\hline Study (year) & $N$ & Glycaemic changes & $\begin{array}{l}\text { Ocular } \\
\text { status }\end{array}$ & $\begin{array}{l}\text { Mean glycaemic } \\
\text { value (mmol/L) }\end{array}$ & Outcome & Mean change (D) & $p$ & $\begin{array}{l}\text { HbA1c } \\
(\%)\end{array}$ & $p$ & DR \\
\hline \multicolumn{11}{|l|}{ Chronic PDM } \\
\hline \multirow[t]{2}{*}{ Gwinup et al. ${ }^{21}$} & 10 & Hyperglycaemia & Phakic & $\Delta 5.6$ & Myopic shift & -0.50 & $<0.050$ & N/A & N/A & None \\
\hline & & & Aphakic & $\Delta 5.6$ & Hyperopic shift & +0.50 & $<0.050$ & $N / A$ & $\mathrm{~N} / \mathrm{A}$ & \\
\hline Okamoto et al. ${ }^{18}$ & 14 & Hypoglycaemia & Phakic & $29.75 \pm 7.80 \dagger$ & Hyperopic shift & +1.47 & $<0.010$ & 11.9 & $<0.005$ & None \\
\hline Huntjens and O'donnell ${ }^{7}$ & N/A & Hyperglycaemia & Aphakic & $\Delta 5.6$ & Hyperopic shift & +0.50 & $<0.050$ & $\mathrm{~N} / \mathrm{A}$ & $\mathrm{N} / \mathrm{A}$ & None \\
\hline Lin et al. ${ }^{22}$ & 5 & Hypoglycaemia & Phakic & $32.55 \pm 12.78 \dagger$ & Hyperopic shift & +1.35 & $<0.050$ & 14.2 & N/A & None \\
\hline Li et al. ${ }^{12}$ & 20 & Hypoglycaemia & Phakic & $19.48 \pm 5.04 \dagger$ & Hyperopic shift & +1.60 & $<0.050$ & 12.2 & $<0.050$ & None \\
\hline Klein et al. ${ }^{23}$ & 2094 & Hyperglycaemia & Phakic & $11.1 \dagger$ & $\begin{array}{l}\text { T1 DM > myopic } \\
\text { T2 DM }\end{array}$ & $\begin{array}{l}\mathrm{T} 1:-0.20 \pm 1.08 \\
\mathrm{~T} 2:+0.48 \pm 0.89\end{array}$ & $<0.001$ & $\mathrm{~N} / \mathrm{A}$ & $\mathrm{N} / \mathrm{A}$ & Mild NPDR \\
\hline \multicolumn{11}{|l|}{ Newly diagnosed PDM } \\
\hline Eva et al. ${ }^{10}$ & 13 & Hyperglycaemia & Phakic & $22.72 \dagger$ & Hyperopia & +2.00 & & $\mathrm{~N} / \mathrm{A}$ & $\mathrm{N} / \mathrm{A}$ & None \\
\hline Giusti et al. ${ }^{19}$ & 20 & Hypoglycaemia & Phakic & $\Delta 14.05$ & Myopic shift & -1.76 & $<0.001$ & 7.3 & $<0.001$ & None \\
\hline Yarbağ et al. ${ }^{25}$ & 130 & Hypoglycaemia & Phakic & $\Delta 11.73$ & Myopic shift & -1.75 & $<0.050$ & $\mathrm{~N} / \mathrm{A}$ & $\mathrm{N} / \mathrm{A}$ & None \\
\hline Verma et al. ${ }^{24}$ & 100 & Hypoglycaemia & Phakic & $\Delta 11.37$ & Myopic shift & -1.50 & $<0.050$ & $\mathrm{~N} / \mathrm{A}$ & $\mathrm{N} / \mathrm{A}$ & NPDR \\
\hline
\end{tabular}

N/A, not available; PDR, proliferative diabetic retinopathy; PDM, people with diabetes mellitus; DR, diabetic retinopathy; $\Delta$, change; NPDR, non-proliferative diabetic retinopathy $\dagger$, Peak BGL.

and aphakic PDM and found that acute changes in four aphakic PDM revealed an increase in transient hyperopia after intravenous glucose injection in aphakic PDM without retinopathy. A scientific review ${ }^{7}$ suggests that changes in the refractive power of aphakic PDM without retinopathy are because the cornea and the posterior capsule of the lens have an effect on refractive error changes. ${ }^{7}$ No study has been conducted on pseudophakic PDM.

\section{Phakic people with diabetes mellitus}

Okamoto et al..$^{18}$ in 2000 conducted a study on 14 phakic PDM and found transient hyperopic shift of +1.47 dioptres (D) after decrease in BGL. Saito et al. ${ }^{26}$ agreed with Okamoto et al. $^{18}$ that there is a direct correlation between the degree of hyperopic shift in refractive error and the BGL changes found in phakic PDM. Studies by Li et al. ${ }^{12}$ in 2010 and Lin et al. ${ }^{22}$ in 2009 found that intensive reduction in BGL caused transient hyperopia changes of $+1.35 \mathrm{D}$ and $+1.60 \mathrm{D}$ in newly diagnosed phakic PDM, resulting in blurred vision in PDM without retinopathy. There is a lack of consensus in studies that compared the influence that T1 DM and T2 DM have on refraction. Klein et al. ${ }^{23}$ found a mean change in refractive error of $-0.20 \mathrm{D}$ and $+0.48 \mathrm{D}$ in $\mathrm{T} 1 \mathrm{DM}$ and $\mathrm{T} 2 \mathrm{DM}$, respectively, and concluded that $\mathrm{T} 1 \mathrm{DM}$ were likely to be slightly more myopic than those with T2 DM $(p<0.01)$.

These studies $18,22,23,24,25$ suggest that the myopic shift in refractive error in phakic PDM was caused by crystalline lens after intravenous glucose injection. The studies ${ }^{7,21}$ conducted on phakic PDM showed that the cornea and the posterior lens capsule have an impact on refractive error changes. The cornea and posterior lens capsule reverse any changes induced by crystalline lens in phakic PDM, thus causing refractive error in the opposite direction of aphakic PDM. ${ }^{7}$

Conversely, few studies ${ }^{10,19,24,25}$ have reported the possibility of increasing myopic shift in refraction under hypoglycaemic conditions in newly diagnosed phakic PDM. Eva et al. ${ }^{10}$ in 1982 studied 12 phakic PDM and found hyperopic shift in refraction when BGL increased in newly diagnosed phakic PDM. In 2003, Giusti et al. ${ }^{19}$ studied 20 newly diagnosed T1 DM phakic PDM and found a mean change of $-1.76 \mathrm{D}$ myopic shift in refraction, with a BGL mean increase of $14.45 \mathrm{mmol} / \mathrm{L}$. Recent studies by Verma et al. ${ }^{24}$ in 2017 and Yarbağ et $a .^{25}$ in 2015 have found that the mean change of $11.73 \mathrm{mmol} / \mathrm{L}$ (hypoglycaemia) produced myopic change of $-1.75 \mathrm{D}$ in newly diagnosed phakic T2 DM $(p<0.05)$.

In summary, there is a transient and permanent direct correlation between the degree of hyperopic shift in refraction and BGL changes in phakic PDM, and a transient correlation in the degree of myopic shift in the refraction of phakic PDM; however, little is known about the effect on pseudophakic PDM. These changes are transient with acute glycaemic changes and permanent in a chronic increase in BGL in PDM. Refractive error changes related to DM could be both transient and chronic in phakic PDM, but relatively little is known on the effect of changes in pseudophakic PDM. The biochemical changes occurring during refractive error changes in phakic PDM are not well understood, whilst the biochemical changes in pseudophakic and aphakic PDM on refraction have not been investigated yet.

The biochemical changes in chronic phakic PDM occur when the crystalline lens has excessively high glucose. Aldose reductase is responsible for the first step in the polyol cycle that reduces glucose to sorbitol, which builds up in the lens. During a shift in the glycaemic state of PDM from hyper- to hypoglycaemia, surplus of glucose moves out of the lens but not sorbitol. Because of the difference in osmotic pressure between the lens and the aqueous humour, water from the aqueous humour moves into the lens, causing swelling with hyperopic shift in refraction. Change in the refractive index of the crystalline lens produces considerably volatile refractive error changes; this is a plausible explanation for the existence of refractive error changes in phakic PDM.7,26,27

\section{Corneal curvature and thickness in people with diabetes mellitus}

The cornea and the crystalline lens are primarily responsible for the refraction of light in the eye. ${ }^{15}$ The cornea is a major 
contributor with approximately two-thirds of refractive power to the eye. ${ }^{7}$ Corneal refractive power can be altered by changes in curvature or corneal thickness, which significantly changes refractive error.

Structural and functional abnormalities of the cornea are caused by its compromised epithelial barrier function and decreased endothelial function owing to DM. Complications associated with DM in the cornea are recurrent corneal erosions, punctate keratitis, decreased sensitivity, delayed wound healing and corneal oedema after vitrectomy. ${ }^{15}$

\section{Corneal curvature}

Table 2 shows various studies describing the effect of glycaemic changes on corneal curvature in PDM. ${ }^{6,12,15,16,18,19}$ Studies have tried to isolate the refractive surface responsible for refractive changes induced by the fluctuating BGL. Sonmez et al. ${ }^{16}$ investigated the effect of intensive glycaemic control on 18 phakic hyperglycaemia-induced changes on refractive properties, with a mean BGL of $19.75 \mathrm{mmol} / \mathrm{L}$ before and $7.42 \mathrm{mmol} / \mathrm{L}$ after treatment. A statistically significant change in corneal topographic keratometric measurements at the flattest corneal meridian occurred after treatment. The mean acute values for the topographic measurements of the flattest axis increased from $43.51 \pm 1.56$ $\mathrm{D}$ on admission to $43.60 \pm 1.60 \mathrm{D}$ at the second examination. This suggests that all refractive procedures, including prescription of spectacles, corneal refractive procedures and lens extraction, should be deferred until normalisation of BGL in PDM.

In 2007, Wiemer et al. ${ }^{15}$ investigated the effect of T1 DM and T2 DM on the cornea with non-diabetics and concluded that phakic PDM had significantly smaller posterior corneal radii (T1 DM: $6.49 \pm 0.04$ and T2 DM: $6.48 \pm 0.04 \mathrm{~mm}$ ) as compared with non-diabetics $(6.64 \pm 0.04 \mathrm{~mm})$. The mean posterior power of cornea was significantly larger statistically $(p<0.05)$ in PDM (T1 DM: $-6.27 \pm 0.03 \mathrm{D}$ and T2 DM: $-6.36 \pm 0.03 \mathrm{D})$ compared with non-diabetics $(-6.17 \pm 0.03 \mathrm{D})$. As a result, the posterior corneal power of phakic PDM varied from that of the non-diabetics $(p<0.01)$. However, the corneal power did not differ statistically between phakic PDM and nondiabetics. In 2008, Wiemer et al. $^{6}$ investigated the effect of acute hyperglycaemia on non-diabetics and found no statistically significant changes in the anterior and posterior corneal curvature and the lens. The authors concluded that sustained and profound hyperglycaemia was required to cause fluctuating vision of the phakic eye.

Giusti et al. ${ }^{19}$ investigated the effect of glycaemic changes in newly diagnosed cases of phakic T1 DM and found no statistically significant changes in anterior corneal power $(p>0.05),{ }^{18}$ lens thickness or anterior chamber depth. Li et al. ${ }^{12}$ in a study conducted in 2010 agreed with Giusti et al. ${ }^{19}$ and found no statistically significant changes during intensive glycaemic control of severe hyperglycaemia in newly diagnosed phakic PDM. Okamato et al. ${ }^{18}$ concluded that hyperopic changes in phakic PDM after intensive glycaemic control were not attributed to morphological changes of the cornea in phakic PDM.

In summary, there are no significant changes in the overall anterior corneal curvature before and after the decrease in BGL in phakic PDM. ${ }^{14,15}$ The mean posterior power of the cornea was larger statistically $(p<0.05)$ in PDM compared with non-diabetics, and the mean posterior curvature was significantly smaller in PDM compared with non-diabetics. However, there was no statistically significant evidence for refractive change in the whole cornea $(p>0.05)$, as the anterior corneal curvature was not affected by changes in BGL. ${ }^{15}$ The flattest corneal meridian showed significant changes during hyperglycaemia ${ }^{16}$ and the posterior radii of the cornea of PDM was significantly smaller, compared to non-diabetics. ${ }^{14}$

Hyperglycaemia and the corneal topographic changes have not been studied well. Excess glucose concentration in the aqueous humour and the cornea can also affect corneal topography by changing corneal hydration, ${ }^{16}$ resulting in significant changes in the posterior radii and power. No studies have yet been conducted on pseudophakic and aphakic PDM.

\section{Corneal thickness}

Table 3 shows various studies describing the effect of glycaemic changes on corneal thickness in PDM. ${ }^{15,17,28}$ In 2008, $\mathrm{Su}$ et al. ${ }^{17}$ investigated the effect of hyperglycaemia and $\mathrm{HbA1c}$ on the central corneal thickness (CCT) using ultrasound pachymetry. On average, chronic changes in BGL in phakic PDM resulted in 6.5- $\mu \mathrm{m}$ thicker central cornea than in non-diabetics, and the mean CCT positively correlated with the high levels of BGL and $\mathrm{HbA1c}$.

Lee et $a .^{28}$ in agreement with Su et al. ${ }^{17}$ found that the CCT were on average significantly thicker in phakic PDM for more than 10 years $(595.9 \pm 4.2 \mathrm{~mm})$, compared with nondiabetics $(567.8 \pm 3.8 \mathrm{~mm} ; p<0.001)$. Su et al. ${ }^{17}$ concluded that hyperglycaemia in phakic PDM may lead to endothelial dysfunction, resulting in stromal hydration and thicker CCT, which could be detected by specular microscopy. Wiemer et al..$^{15}$ disagreed with Lee et al. ${ }^{28}$ and reported that there is no correlation between CCT and the age of PDM.

The average of at least 3 months (HbA1c) affects CCT more than acute changes in BGL. Proliferative diabetic retinopathy had thicker CCT than non-proliferative diabetic retinopathy. ${ }^{17}$ A study conducted by Busted et al. ${ }^{29}$ found the mean cell density to be $2686 \pm 356$ cells $/ \mathrm{mm}^{2}$ and $2853 \pm 386$ cells $/ \mathrm{mm}^{2}$ in those with and without proliferative diabetic retinopathy, respectively. Correlation between thicker CCT and diabetic retinopathy suggests that CCT may be an indicator of the risk of retinal complications in PDM. ${ }^{29}$

Phakic PDM is often associated with increased $\mathrm{CCT},{ }^{17}$ but transient fluctuation of BGL rendered no effect in the corneal thickness. Hyperglycaemia may cause decreased corneal 
TABLE 2: Effect of glycaemic changes on corneal curvature in people living with Diabetes Mellitus.

\begin{tabular}{|c|c|c|c|c|c|c|c|c|c|c|}
\hline $\begin{array}{l}\text { Study } \\
\text { (year) }\end{array}$ & $N$ & $\begin{array}{l}\text { Mean glycaemic } \\
\text { value (mmol/L) }\end{array}$ & $\begin{array}{l}\text { Mean } \\
\text { HbA1c (\%) }\end{array}$ & $\begin{array}{l}\text { Ocular } \\
\text { status }\end{array}$ & Tool & $\begin{array}{l}\text { Mean anterior } \\
\text { corneal surface }\end{array}$ & $p$ & $\begin{array}{l}\text { Mean posterior } \\
\text { corneal surface }\end{array}$ & $p$ & DR \\
\hline \multicolumn{11}{|c|}{ Hypoglycaemic changes } \\
\hline Okamoto et al. ${ }^{18}$ & 28 & $29.75 \pm 7.80 \dagger$ & 11.90 & Phakic & N/A & 44.06 to 43.96 & $>0.005$ & $\mathrm{~N} / \mathrm{a}$ & N/A & None \\
\hline Giusti et al. ${ }^{19}$ & 20 & $\Delta 14.45$ & 7.00 & Phakic & Computerised video keratoscope & 44.76 to 44.94 & $>0.05$ & N/A & N/A & None \\
\hline Sonmez et al. ${ }^{16}$ & 18 & $\Delta 12.4$ & 11.38 & Phakic & C-scan corneal topography & N/A & $\mathrm{N} / \mathrm{A}$ & N/A & N/A & None to NPDR \\
\hline Li et al. ${ }^{12}$ & 20 & $19.48 \pm 5.04 \dagger$ & 12.20 & Phakic & N/A & 44.70 to 44.94 & $>0.050$ & N/A & N/A & None \\
\hline \multicolumn{11}{|c|}{ Hyperglycaemic changes } \\
\hline Wiemer et al. ${ }^{15}$ & 272 & $\begin{array}{l}\mathrm{T} 1: 9.7 \pm 4.6 \dagger \\
\mathrm{T} 2: 7.9 \pm 3.2 \dagger\end{array}$ & $\begin{array}{l}\mathrm{T} 1: 8.1 \pm 1.6 \\
\mathrm{~T} 2: 7.5 \pm 1.4\end{array}$ & Phakic & Scheimpflug imaging & $\begin{array}{l}\mathrm{T} 1: 47.8 \pm 0.2 \\
\mathrm{~T} 2: 48.1 \pm 0.2\end{array}$ & $>0.050$ & $\begin{array}{l}\mathrm{T} 1:-6.17 \pm 0.04 \\
\mathrm{~T} 2:-6.19 \pm 0.04\end{array}$ & $<0.001 *$ & None to PDR \\
\hline Wiemer et al. ${ }^{6}$ & 5 & $\Delta 14.00$ & $\mathrm{~N} / \mathrm{A}$ & Phakic & Scheimpflug imaging & No change & $>0.050$ & No change & & None \\
\hline
\end{tabular}

N/A, not available; DR, diabetic retinopathy; NPDR, non-proliferative diabetic retinopathy; PDR, proliferative diabetic retinopathy; $\Delta$, change.

$\dagger$, Peak BGL.

*, Statistically significant observation.

TABLE 3: Effect of glycaemic changes on corneal thickness in people with diabetes mellitus.

\begin{tabular}{llllll}
\hline Study & $N$ & Glycaemic change & Tool & CCT & Outcome (CCT in DM) \\
\hline Lee et al. ${ }^{28}$ & 300 & Hyperglycaemia & Ultrasound pachymetry & $\begin{array}{l}\text { DM: } 588.2 \pm 2.7 \mu \mathrm{m} \\
\text { Non-DM: } 567.8 \pm 3.8 \mu \mathrm{m}\end{array}$ & Thicker \\
Su et al. ${ }^{17}$ & 3280 & Hyperglycaemia & Ultrasound pachymetry & $\begin{array}{l}\text { DM: } 547.2 \mu \mathrm{m} \\
\text { Non-DM: } 539.3 \mu \mathrm{m}\end{array}$ & Thicker \\
Wiemer et al. ${ }^{15}$ & 272 & Hyperglycaemia & Scheimpflug imaging & $\begin{array}{l}\text { T1: } 0.586 \pm 0.003 \text { (SE) mmT2: } 0.578 \pm 0.003 \text { (SE) } \\
\text { mmControl: } 0.578 \pm 0.004 \text { (SE) mm }\end{array}$ & $>0.190$ \\
\hline
\end{tabular}

$\mathrm{CCT}$, central corneal thickness; DM, diabetes mellitus; $\mathrm{SE}$ : standard error.

*, Statistically significant observation.

endothelial function, which results in influx of water to the cornea and thicker CCT. Corneal endothelial abnormalities, such as polymorphism, polymegathism, decrease in percentage of hexagonal cells, higher coefficient of variation and increased CCT, have been noted on specular microscopy in PDM. There is a lack of evidence on the effect of transient changes of BGL on the corneal curvature of pseudophakic and aphakic PDM and non-diabetics.

\section{Contrast sensitivity in people with diabetes mellitus}

Contrast sensitivity is a function of the retina, and it evaluates the central vision. ${ }^{30}$ It is the ability of the visual system to realise differences between objects and background to the finest detail. In a patient with diabetes, CS may be reduced even before the development of diabetic retinopathy and even when VA is normal. Hence, measuring CS may be a useful tool for early detection of abnormalities in retinal function in PDM..$^{30}$ Acute hyperglycaemia in PDM is often associated with transient subjective visual disturbances, and the CS test is used to assess functional visual disturbances. ${ }^{31}$ Dynamic testing of CS is the assessment of CS when either the target or the patient is in motion, whilst the static testing of CS is when both target and patient are stationary. Table 4 describes the effect of glycaemic changes on CS in PDM and is elaborated below.

In 1982, Ghafour et al. ${ }^{32}$ investigated the effect of DM with and without retinopathy on CS and found that phakic PDM had a permanent significant increase in threshold at higher frequencies compared to non-diabetics, thus suggesting poorer CS. ${ }^{32}$ In 1992, Di Leo et al. ${ }^{33}$ found that CS was significantly reduced in contrast threshold of PDM during hyperglycaemia compared to non-diabetics. Di Leo et al. ${ }^{33}$ also found that $\mathrm{HbAlc}$ significantly correlated with CS thresholds in both dynamic and static tests, $p<0.05$ and $p<0.05$, respectively.
It is thought that hyperglycaemia is linked to the development of diabetic retinopathy; thus, higher $\mathrm{HbA} 1 \mathrm{c}$ is also associated with the development of retinopathy.

In 1995, Mangouritsas et al. ${ }^{31}$ investigated the effect of induced hyperglycaemia in phakic T2 DM without retinopathy on CS and found a statistically significant difference between euglycaemia $(6.4 \mathrm{mmol} / \mathrm{L})$ and hyperglycaemia $(15.4 \mathrm{mmol} / \mathrm{L})$. There was no statistical significance between DM and CS duration. The latest study conducted by Rashmi et al. ${ }^{30}$ in 2016 on disagreement found that as the duration increases and glycaemic control worsens, CS decreases. In 2003, Stavrou et al..$^{34}$ investigated the effect of later CS changes in early diabetic retinopathy and found that CS was reduced in phakic PDM, compared with nondiabetics. Using the Pelli-Robson Chart, Stavrou et al. ${ }^{34}$ and Noticewala et al. ${ }^{35}$ found similar results in significant loss of CS clinically and statistically.

Andrade et al. ${ }^{13}$ found lower mean monocular CS in phakic PDM with no retinopathy at all spatial frequencies, compared with phakic non-diabetics. Statistical significance was found in two out of 11 (15 cycles per degree [CPD] and 30 CPD) spatial frequencies tested $(p<0.05)$. Phakic PDM without retinopathy showed increased thresholds at higher spatial frequencies tested. ${ }^{13}$ Phakic PDM with retinopathy had statistically lower mean monocular CS than non-diabetics at all spatial frequencies. This was in agreement with Rashmi et al. ${ }^{30}$ who also found that CS was significantly lower in PDM with retinopathy than in non-diabetics $(p<0.05)$ or in PDM without retinopathy $(p<0.05)$.

Psychophysical methods in PDM showed loss of foveal vision. Visual testing by CS can significantly advance the evidence of neuropathology of PDM. Phakic PDM have a significant loss in CS in spite of the fact that the patient has 
TABLE 4: Effect of glycaemic changes on contrast sensitivity function in people with diabetes mellitus.

\begin{tabular}{|c|c|c|c|c|c|c|c|c|}
\hline Study & $N$ & Diabetic status & Glycaemic state & Ocular status & Tool & $p$ & Outcome & DR \\
\hline Ghafour et al. ${ }^{32}$ & 179 & T1 DM and T2 DM & Hyper & Phakic & Arden Grating Test & $<0.0001^{*}$ & $\downarrow C S$ & None to PDR \\
\hline Di Leo et al. ${ }^{33}$ & 24 & T1 DM & Hyper & Phakic & ASA400 black and white film & $<0.0200^{*}$ & $\downarrow C S$ & None \\
\hline Mangouritsas et al. ${ }^{31}$ & ${ }^{12} 20$ & T2 DM & Hyper & Phakic & CSV-100 CS test & $>0.0500$ & No observation & None \\
\hline Stavrou et al. ${ }^{34}$ & 44 & T2 DM & Hyper & Phakic & Pelli-Robson Chart (Letter CS) & $<0.0010^{*}$ & $\downarrow C S$ & None to moderate NPDR \\
\hline Andrad e et al. ${ }^{13}$ & 27 & $\mathrm{~T} 2 \mathrm{DM}$ & Hyper & Phakic & Contrast sensitivity test & $<0.0500^{*}$ & $\downarrow C S$ & None \\
\hline Rashmi et al. ${ }^{30}$ & 200 & $\mathrm{~T} 2 \mathrm{DM}$ & Hyper & Phakic & Appasamy I Chart & $<0.0330^{*}$ & $\downarrow C S$ & None \\
\hline Noticewala et al. ${ }^{35}$ & 114 & $\mathrm{~T} 1 \mathrm{DM}$ and $\mathrm{T} 2 \mathrm{DM}$ & Hyper & Phakic & Pelli-Robson chart & $<0.0500^{*}$ & $\downarrow C S$ & None to NPDR \\
\hline Mirković et al. ${ }^{36}$ & 20 & T1 DM and T2 DM & Hyper & Phakic & Low-contrast ETDRS & $<0.0500^{*}$ & $\downarrow C S$ & None to NPDR \\
\hline
\end{tabular}

Hyper, hyperglycaemia; DR, diabetic retinopathy; NPDR, non-proliferative diabetic retinopathy; PDR, proliferative diabetic retinopathy; CS, contrast sensitivity; ETDRS, early treatment diabetic retinopathy study.

$*$, Statistically significant observation.

retinopathy or not. Contrast sensitivity can be used to grade and monitor the progression of diabetic retinopathy, as there is a greater loss of CS in severe diabetic retinopathy. Contrast sensitivity detects early changes of visual function in chronic T1 DM before the appearance of diabetic retinopathy. Static testing of CS in all PDM found similar results with loss of CS at both low and high spatial frequencies. No study has been conducted on aphakic and pseudophakic PDM to compare the effect of transient BGL changes on CS.

\section{Visual acuity in people with diabetes mellitus}

Visual acuity is a well-known estimation of visual capacity in light of the fact that the test is effortlessly regulated. People with DM complaining of fluctuating VA present with symptoms such as blurred vision with spectacles when driving and reading. Visual acuity testing is the highest quality-level' test for essential results of clinical trials. ${ }^{37}$ Table 5 describes the effect of glycaemic changes on VA in PDM and is elaborated upon below.

Okamoto et al. ${ }^{18}$ investigated the effect of hypoglycaemia in phakic PDM and found reduced VA when BGL decreased. In contrast Guisti et al. ${ }^{19} 2003$ found no statistically significant difference between VA and changes in BGL. Stavrou et al. ${ }^{34}$ conducted a study on phakic T2 DM using LogMAR (Bailey-Lovie Chart) and measured the reduction in VA in PDM during a hyperglycaemic state. This suggests that in spite of the glycaemic state in PDM, the VA will be affected.

Wiemer et al. ${ }^{6}$ conducted a study on acute hyperglycaemia in phakic non-diabetics using the Snellen Acuity Chart and found reduced VA. Therefore, it is assumed that fluctuating vision in PDM is not owing to a contributing factor of higherorder aberrations but owing to changes in lower-order aberrations of the eye. In contrast to these findings, Wiemer et al. ${ }^{38}$ when measuring higher-order aberration, found small changes before and after the patient complained of blurred vision, thus suggesting that subjective symptoms of poor vision during hyperglycaemia are not because of changes in the refractive properties of phakic PDM.

Noticewala et al. ${ }^{35}$ conducted a study on phakic PDM using the Snellen Acuity Chart and found a statistically significant reduction in VA in PDM, compared with non-diabetics. The mean Snellen equivalent best-corrected VA for right eye in PDM was 6/9 and with non-diabetics it was 6/6. The mean Snellen equivalent best-corrected VA for left eye in PDM was $6 / 9$ and with non-diabetics it was 6/6.

Jurangal et al. ${ }^{37}$ conducted a study to assess VA in phakic PDM and found that maximum number of PDM (30\%) have the best-corrected VA of $6 / 18$. In contrast to this, maximum number of non-diabetics (38\%) have the best-corrected VA of $6 / 9$; both results were statistically significant. Based on the findings, it was concluded that non-diabetic eyes were found to have the best-corrected VA than PDM owing to macular degeneration, cataract diabetic maculopathy and corneal haziness.

Transient BGL in phakic PDM has been known for many years to cause changes in VA, but there is a lack of evidence on the effect in pseudophakic patients. There is no correlation between BGL and VA in phakic PDM. Anecdotal evidence suggests that fluctuations in BGL cause blurred vision in patients. Wiemer et al. ${ }^{38}$ proved that the refractive component of the eyes is not affected by fluctuations in BGL. The generally accepted theory is that acute fluctuations of VA in PDM are primarily because of lens swelling and decreased refractive index. ${ }^{21}$ No study has been conducted to compare the effect on VA in aphakic and pseudophakic PDM.

\section{Discussion}

Changes in refractive error could be because of fluctuating BGL. Therefore, it is vital to enquire about BGL when examining PDM. Prescribing spectacles is ill-advised if BGL is uncharacteristically high or low during examination, and it is important to educate PDM about the effect of DM on eyes and the complications as a result of uncontrolled BGL. ${ }^{34}$ Diabetes mellitus should be controlled before spectacles are prescribed. Optometrists as primary eye care providers assess and monitor a large number of PDM. Optometrists may consider undiagnosed DM when a patient complains of fluctuating VA.

Transient refractive changes owing to fluctuations in BGL are known signs in phakic PDM. Myopic shifts ${ }^{12,18,21,22}$ and hyperopic shifts ${ }^{10,19,24,25}$ have been reported in phakic PDM during hyperglycaemia. In newly diagnosed phakic PDM, high BGL results in hyperopic shift in refraction, whilst in chronic phakic PDM, myopic shift in refraction is noted. 
TABLE 5: Effect of glycaemic changes on visual acuity in people with diabetes mellitus.

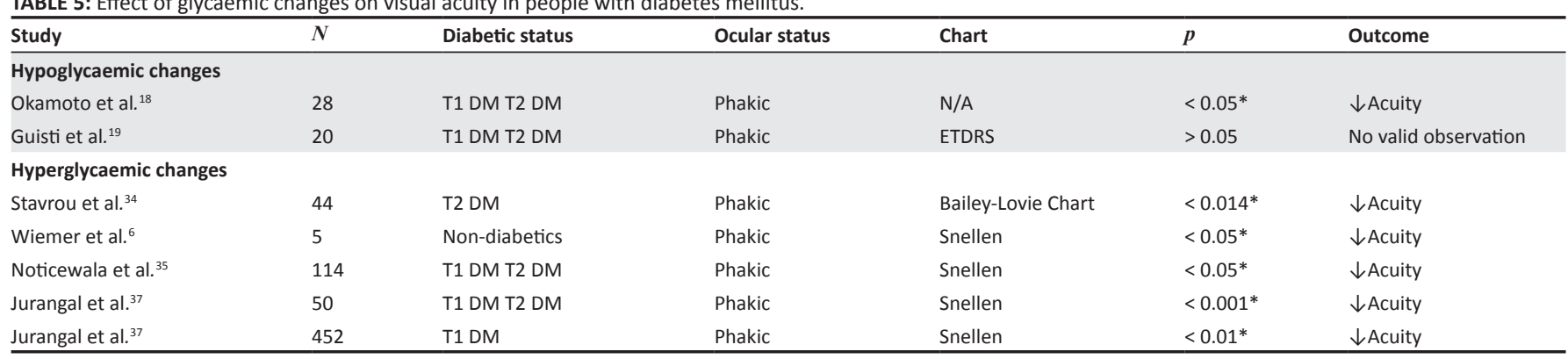

$\mathrm{N} / \mathrm{A}$, not available; ETDRS, early treatment diabetic retinopathy study.

*, Statistically significant observation.

Hyperglycaemia causes hyperopia in aphakic $\mathrm{PDM}^{7,18,19}$ and myopia in chronic phakic PDM. ${ }^{7,21}$ These data indicate that myopic shift in refractive error of phakic PDM was caused by the crystalline lens. The sorbitol pathway causes accumulation of sorbitol and fructose in the lens, which decreases refractive index of the lens, causing hyperopic shift in refraction..$^{21}$ The cornea and the posterior lens capsule in aphakic PDM result in a hyperopic shift in the refractive error of aphakic PDM. However, as change in the refractive error was opposite in direction in phakic PDM, compared with aphakic PDM, the crystalline lens alters changes made by the cornea and the posterior lens capsule. ${ }^{7}$

Changes in refractive power in aphakic PDM without retinopathy are because of the cornea and the posterior lens capsule having an influence on refractive error changes. This may be a possibility in pseudophakic PDM considering that the IOL is inert. No study is conducted on refraction in pseudophakic PDM.

Hyperglycaemia has more influence on posterior corneal power as compared to the anterior corneal power. However, the contribution of posterior corneal power is insignificant to the total refractive error of the eye, and even in the overall corneal power. Therefore, hyperglycaemia has insignificant effect on the total corneal power. ${ }^{15}$ People with diabetes mellitus had thicker CCT as compared to non-diabetics of the same age group; this is because of disruption in corneal endothelium by hyperglycaemia. ${ }^{15}$ Metabolic control of DM plays a vital role in corneal thickness as $\mathrm{HbA1c}$, which is not controlled, presents with thicker corneas as compared with controlled HbA1c. ${ }^{17}$ No study has been conducted on the cornea in pseudophakic PDM.

Previous studies ${ }^{30,35,36}$ have found that phakic PDM have reduced CS as compared to non-diabetics during hyperglycaemic state. Hyperglycaemia in PDM resulted in reduced CS as compared to euglycaemia. ${ }^{31}$ No study has been conducted on pseudophakic PDM. Visual acuity has been found to be reduced in both phakic PDM $^{6,35,37}$ and nondiabetics $^{6}$ during hyperglycaemia. No study has been conducted on VA in pseudophakic and aphakic PDM. Psychophysical visual assessment methods in PDM show impairment of foveal vision. Testing of vision by psychophysical methods can significantly contribute to the evidence of neuropathological abnormalities even before signs are visible.

Figure 1 is a schematic that serves as a summary for practitioners to consider when assessing PDM who are phakic and aphakic based on the studies discussed in the review article.

Methodological sources of variations were identified in the studies included in this review. Different instrumentation and techniques, methods of data analysis, and population types and representativeness may be attributed to variation in findings.

\section{Limitations of the present review and previous studies}

Limitation of the current review is that only literature reported in the English language was reviewed; articles reported in other languages were not reviewed. Secondly, only peer-reviewed electronic journal publications were reviewed; grey literature was omitted. The most significant limitation of the present review is that no study was found on aphakic PDM.

The eligibility criteria that are vital in understanding the studied sample and interpreting and assessing the study validity were not indicated in some studies. The majority of the studies did not detail their sampling strategies and how sample sizes were derived, whilst some studies used small sample sizes with a consequently low statistical power. Mean glycaemic values were not stated in some studies. Few studies have been conducted on aphakic PDM, and there is a significant paucity of studies on pseudophakic PDM.

\section{Recommendations for future studies}

A study of the mechanism involved between BGL and refractive error in PDM is necessary. More studies with random sampling and larger sample sizes would yield more conclusive results. More studies are to be conducted on pseudophakic and aphakic PDM on vision. To enable reproducibility of a study by other researchers, authors should detail adequately all testing protocols. As there were conflicting reports on the nature of refraction in phakic PDM, more research is to be conducted. More studies are to be conducted on phakic, aphakic and pseudophakic PDM; 


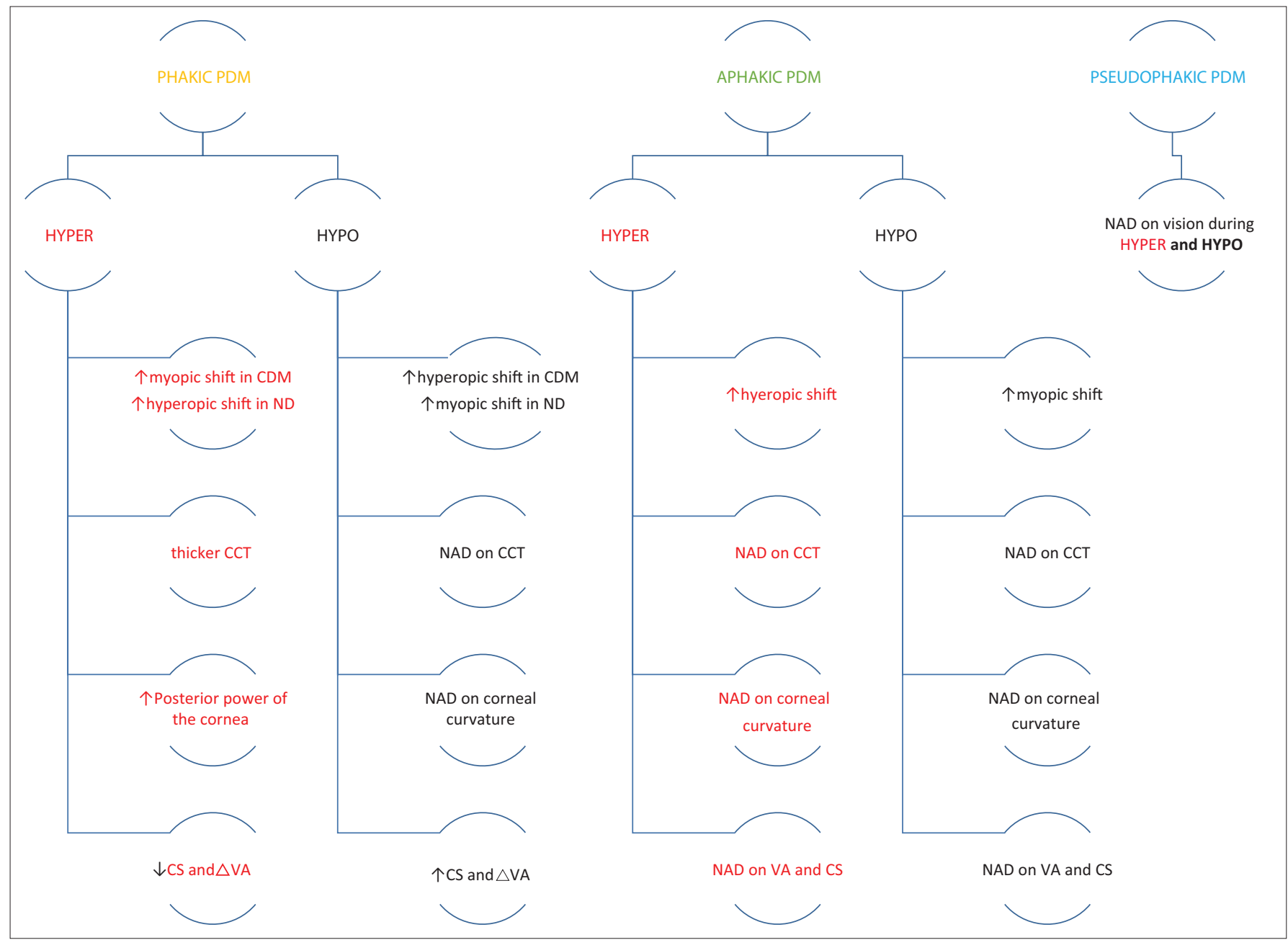

ND, newly diagnosed; CDM, chronic diabetes mellitus; NAD, no available data; CS, contrast sensitivity; VA, visual acuity; CCT, central corneal thickness; HYPO, hypoglycaemia; HYPER, hyperglycaemia; $\uparrow$, increase: $\downarrow$ :, decrease; $\Delta$, change.

FIGURE 1: A schematic summary of the effects of glycaemic changes on vision in phakic, aphakic and pseudophakic people with diabetes mellitus.

T1 DM and T2 DM; refractive error, CCT, corneal curvature, CS and VA.

\section{Conclusion}

In spite of the lack of recent evidence on pseudophakic PDM, rise in BGL in chronic PDM causes myopia in phakic PDM, whilst in aphakic PDM, it causes hyperopic shift in refraction. Conversely, hypoglycaemia causes myopic shift in refraction in newly diagnosed phakic PDM. The underlying mechanism governing the relationship between BGL and refractive error is not yet fully understood. In aphakic PDM, it has not been concluded whether refractive error changes seen are because of changes in the posterior corneal power, posterior capsular or refractive index of aqueous humour and axial length.

There are no significant changes in the overall anterior corneal curvature before and after glycaemic control in phakic PDM; however, the flattest corneal meridian showed significant changes. When taking history of PDM, it seems vital to know BGL before eye examination, as the latency of acute changes appears to be short, being in order of minutes.
Contrast sensitivity is a useful tool in detecting incipient diabetic retinopathy changes in PDM as compared to nondiabetics, whilst VA is unable to do so. This shows that in PDM, if incipient DR is present, CS can determine whether a functional deficit is present or absent. Therefore, CS and VA should be administered together as part of routine examination, as it is more likely to show early functional deficits that cannot be detected on fundus examination and VA, especially in those who have not been diagnosed with DM.

It should be clearly understood that high BGL induces transient myopia and hyperopia in chronic phakic PDM and aphakic PDM, respectively, whilst in newly diagnosed phakic PDM, hyperopia is noted. Transient refractive changes are more dependent on the value of BGL; therefore, it is imperative to postpone all refractive procedures till the normalisation of glucose level. No study has been conducted on the effect of glycaemic changes on vision in pseudophakic PDM.

\section{Acknowledgements}

This article forms part of L.M.'s Masters in Optometry research study (BE 230/18) under the supervision of A.J.M. 


\section{Competing interests}

The authors declare that they have no financial or personal relationships that may have inappropriately influenced them in writing this article.

\section{Authors' contributions}

L.M. contributed towards introduction, results and the final research presentation. A.J.M. was the project facilitator and supervisor.

\section{Funding information}

This study was funded by CHS scholarship (College of Health Sciences, University of KwaZulu-Natal).

\section{Data availability statement}

Data sharing is not applicable to this article as no new data were created or analysed in this study.

\section{Disclaimer}

The views and opinions expressed in this article are those of the authors and do not necessarily reflect the official policy or position of any affiliated agency of the authors.

\section{References}

1. Javadi MA, Zarei-Ghanavati S. Cataracts in diabetic patients: A review article J Ophthalmic Vis Res [serial online]. 2008 Jan [cited 2018 Nov 19]: 3(1):52-65. Available from: http://www.ncbi.nlm.nih.gov/pubmed/23479523

2. Sahadew N, Podiatry B, Singaram VS, et al. Distribution, incidence, prevalence and default of patients with diabetes mellitus accessing public healthcare in the 11 districts of KwaZulu-Natal, South Africa. SAMJ. 2016;106(4):389-393. https://doi. org/10.7196/SAMJ.2016.v106i4.10143

3. Birgit O. Prevalence of diabetes in South Africa. Health24 [homepage on the Internet]. 2017 [cited 2017 Aug 15]. Available from: http://www.health24.com/ Medical/Diabetes/About-diabetes/Diabetes-tsunami-hits-South-Africa-20130210

4. Fauci AS, Braunwald E, Kasper DL. Harrison's manual of medicine. Igarss; 2014.

5. Elizabeth $\mathrm{H}$. Types of blood glucose tests [homepage on the Internet]. 2012 [cited 2017 Aug 15]. Available from: http://www.diabetesmonitor.com/educationcenter/diabetes-basics/types-of-blood-glucose-tests.htm

6. Wiemer NGM, Eekhoff EMW, Simsek S, et al. Refractive properties of the healthy human eye during acute hyperglycemia. Graefe's Arch Clin Exp Ophthalmo 2008;246(7):993-998. https://doi.org/10.1007/s00417-008-0810-y

7. Huntjens B, O'donnell C. Refractive error changes in diabetes mellitus. Optom Pract [serial online]. 2006 [cited 2016 Sep 13]; 7(73):103-114. Available from http://openaccess.city.ac.uk/6185/

8. National Eye Institute. Cataracts. [homepage on the Internet]. [cited 2017 Sep 5] Available from: https://nei.nih.gov/faqs/cataract-pseudophakia

9. Babizhayev MA, Yegorov YE. Reactive oxygen species and the aging eye. Am J Ther [serial online]. 2016 [cited 2018 Feb 26]; 23(1):e98-e117. Available from: http:// www.ncbi.nlm.nih.gov/pubmed/21048433

10. Eva PR, Pascoe PT, Vaughan DG. Refractive change in hyperglycaemia: Hyperopia, not myopia. Br J Ophthalmol. 1982;66(8):500-505. https://doi. org/10.1136/bjo.66.8.500

11. Mitchell S, Wick B. Clinical management of binocular vision: Heterophoric, accommodative, and movement disorders [homepage on the Internet]. 2014: 3rd edn t8C\&printsec=frontcover\&dq=sheiman+and+wick\&hl=en\&sa=X\&ved=0ahUKEwjlvs

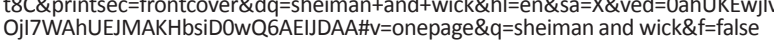

12. Li H-Y, Luo G-C, Guo J, Liang Z. Effects of glycemic control on refraction in diabetic patients. Int J Ophthalmol [serial online]; 2010;3(2):158-160. Available from: http://www.pubmedcentral.nih.gov/articlerender.fcgi?artid=3340779\&tool=pm entrez\&rendertype=abstract

13. Andrade LCO, Souza GS, Lacerda EMC, et al. Influence of retinopathy on the achromatic and chromatic vision of patients with type 2 diabetes. BMC Ophthalmo [serial online]; 2014;14(1):104. Available from: http://bmcophthalmol.biomedcentral. com/articles/10.1186/1471-2415-14-104

14. Wiemer NGM, Dubbelman M, Kostense PJ, Ringens PJ, Polak BCP. The influence of diabetes mellitus type 1 and 2 on the thickness, shape, and equivalent refractiv index of the human crystalline lens. Ophthalmology. 2008;115(10):1679-1686. https://doi.org/10.1016/j.ophtha.2008.03.019
15. Wiemer NGM, Dubbelman M, Kostense PJ, Ringens PJ, Polak BCP. The influence of chronic diabetes mellitus on the thickness and the shape of the anterior and posterior surface of the cornea. Cornea [serial online]. 2007;26(10):1165-1170. Available from: http://www.ncbi.nlm.nih.gov/pubmed/18043169

16. Sonmez B, Bozkurt B, Atmaca A, Irkec M, Orhan Me, Aslan U. Effect of glycemic control on refractive changes in diabetic patients with hyperglycemia. Cornea [serial online]. 2005;24(5):531-537. Available from: http://journals.Iww.com/ corneajrnl/Abstract/2005/07000/Effect_of_Glycemic_Control_on_Refractive_ corneajrnl/Abstract.aspx
Changes.3.asp

17. Su DHW, Wong TY, Wong WL, et al. Diabetes, hyperglycemia, and central corneal thickness. The Singapore Malay Eye Study. Ophthalmology. 2008;115(6):964-969. thickness. The Singapore Malay Eye Study. Oph
https://doi.org/10.1016/j.ophtha.2007.08.021

18. Okamoto $\mathrm{F}$, Sone $\mathrm{H}$, Nonoyama $\mathrm{T}$, Hommura $\mathrm{S}$. Refractive changes in diabetic patients during intensive glycaemic control. $\mathrm{Br} J$ Ophthalmol [serial online] 2000:84(10):1097-1102. Available from: http://www.pubmedcentral.nih.gov/ articlerender.fcgi?artid $=1723257 \&$ tool $=$ pmcentrez\&rendertype $=$ abstract $\% 5 \mathrm{Cnht}$ articlerender.fcgi?artid=1723257\&tool=pmcentrez
tp://bjo.bmj.com/cgi/doi/10.1136/bjo.84.10.1097

19. Giusti C. Transient hyperopic refractive changes in newly diagnosed juvenile diabetes. Swiss Med Wkly. 2003;133(13-14):200-205.

20. Ebeigbe JA, Osaiyuwu A. Transient refractive changes in a newly diagnose. J Niger Optom Assoc. 2009;15:28-32. https://doi.org/10.4314/jnoa.v15i1.55607

21. Gwinup $G$, Villarreal A. Relationship of serum glucose concentration to changes in refraction. Diabetes [serial online]. 1976 [cited 2017 Aug 15]; 25(1). Available from: http://diabetes.diabetesjournals.org/content/25/1/29

22. Lin SF, Lin PK, Chang FL, Tsai RK. Transient hyperopia after intensive treatment of hyperglycemia in newly diagnosed diabetes. Ophthalmologica. 2009;223(1): 68-71. https://doi.org/10.1159/000173714

23. Klein BEK, Lee MS, Klein R. Refraction in adults with diabetes. Arch Ophthalmol [serial online]. 2011;129(1):56. Available from: http://archopht.jamanetwork. com/article.aspx?doi=10.1001/archophthalmol.2010.322

24. Verma DS, Gupta DP, Shakeet DD. Refractive changes in a newly diagnosed diabetic patients. IOSR J Dent Med Sci [serial online]. 2017 [cited 2018 May 5] 16(03):54-57. Available from: http://www.iosrjournals.org/iosr-jdms/papers/ Vol16-issue3/Version-4/01603045457.pdf

25. Yarbağ A, Yazar H, Akdoğan M, Pekgör A, Kaleli S. Refractive errors in patients with newly diagnosed diabetes mellitus. Pakistan J Med Sci [serial online] 2015 [cited 2017 Sep 5];31(6):1481-1484. Available from: http://www. pubmedcentral.nih.gov/articlerender.fcgi?artid $=4744305 \&$ tool=pmcentrez\&re ndertype $=$ abstract

26. Saito $\mathrm{Y}$, Ohmi G, Kinoshita S, et al. Transient hyperopia with lens swelling at initial therapy in diabetes. Br J Ophthalmol [serial online]. 1993 [cited 2017 Sep 5];77(3): 145-148. Available from: http://www.pubmedcentral.nih.gov/articlerender.fcgi? artid $=504458 \&$ tool $=$ pmcentrez\&rendertype $=$ abstract

27. Mathebula SD. Polyol pathway: A possible mechanism of diabetes complications in the eye. Afr Vission Eye Health. 2015;74(1), Art. \#13, 5 pages. https://doi. org/10.4102/aveh.v74i1.13

28. Lee JS, Oum BS, Choi HY, Lee JE, Cho BM. Differences in corneal thickness and corneal endothelium related to duration in diabetes. Eye. 2006;20(3):315-318. https://doi.org/10.1038/sj.eye.6701868

29. Busted N, Olsen T. Clinical observations on the corneal thickness and the corneal endothelium in diabetes mellitus. Br J Ophthalmol. 1981;65(10):687-690. https:// doi.org/10.1136/bjo.65.10.687

30. Rashmi S, Varghese RC, Anupama B, Hegde V, Jain R, Kotian H. Contrast sensitivity in diabetic patients without retinopathy and it's correlation with the duration of diabetes and glycemic control. IOSR J Dent Med Sci [serial online]. 2016 [cited 2018 Nov 5];15(08):11-13. Available from: http://iosrjournals.org/iosr-jdms/ papers/Vol15-Issue 8/Version-6/B1508061113.pdf

31. Mangouritsas G, Katoulis E, Kepaptsoglou O, Zoupas C. Effect of induced hyperglycemia on contrast sensitivity function in insulin-dependent diabetic patients. Ophthalmologe [serial online]. 1995 [cited 2017 Sep 5]; 92(2):142-147. Available from: http://www.ncbi.nlm.nih.gov/pubmed/7780272

32. Ghafour IM, Foulds WS, Allan D, McClure E. Contrast sensitivity in diabetic subjects with and without retinopathy. Br J Ophthalmol. 1982;66(8):492-495. https://doi.org/10.1136/bjo.66.8.492

33. Di Leo MA, Caputo S, Falsini B, et al. Nonselective loss of contrast sensitivity in visual system testing in early type 1 diabetes. Diabetes Care [serial online]. 1992 [cited 2017 Sep 5]; 15(5):620-625. Available from: http://care.diabetesjournals. org/content/15/5/620

34. Stavrou EP, Wood JM. Letter contrast sensitivity changes in early diabetic retinopathy. Clin Exp Optom. 2003;86(3):152-156. https://doi.org/10.1111/j.1444-0938.2003. tb03097.x

35. Noticewala V, Shastri M. A study of contrast sensitivity changes in normal individual and diabetic patients with and without diabetic retinopathy. Int J Res Med Sci. 2017;5(11):4840-4845. https://doi.org/10.18203/2320-6012.ijrms20174930

36. Mirković J, Risimić D. Contrast sensitivity in patients with diabetes mellitus. Med Podml [serial online]. 2018;69(4):35-39. Available from: https://scindeks.ceon.rs/ Article.aspx?artid=0369-15271804035M

37. Jurangal A, Singh A, Dhaliwal RK. Assessment of visual acuity among diabetic patients. Int J Contemp Med Res ISSN. 2017;4(6):1311-1314.

38. Wiemer NGM, Dubbelman M, Ringens PJ, Polak BCP. Measuring the refractive properties of the diabetic eye during blurred vision and hyperglycaemia using aberrometry and Scheimpflug imaging. Acta Ophthalmol. 2009;87(2):176-182. https://doi.org/10.1111/j.1755-3768.2008.01212.x 